\title{
Mountain tourism in Europe
}

\author{
Stefano Duglio ${ }^{1}$ and Riccardo Beltramo ${ }^{2}$
}

\begin{abstract}
${ }^{1}$ Department of Management \& NatRisk, Research centre on natural risk in mountain and hilly environments, University of Torino, 218 bis, Corso Unione Sovietica, IT10134, Torino, Italy; Emails: stefano.duglio@unito.it

2 Department of Management \& NatRisk, Research centre on natural risk in mountain and hilly environments, University of Torino, 218 bis, Corso Unione Sovietica, IT10134, Torino, Italy; Emails: riccardo.beltramo@unito.it
\end{abstract}

Mountains are the second most popular tourism destinations in the world, following coast and island resorts. They account for about $15 \%$ of worldwide tourism, generating a revenue between 70 and 90 billion U.S. dollars per year (UNEP, 2007; UNEP, University of Geneva and University of Bern, 2014). Mountain tourism is a challenging and complex phenomenon that meets a vast range of tourist's needs - nature, relax, sports, leisure, culture, health and wellness.

This special issue of the European Journal of Tourism Research on mountain tourism in Europe was proposed with the aim to encourage the debate among scholars on different European mountain tourism views and perspectives, by presenting specific case studies. We have received 10 manuscripts to be considered for publication; 3 of them passed the review process and constitute this special issue section of the journal.

The first contribution, titled "Understanding the role of destination imagery in mountain destination choice: evidence from an exploratory research", by Arthur Araújo, Lucília Cardoso, Noelia Araújo and Francisco Dias, deals with the imagery of mountain tourism destinations. In doing so, the authors 'read' the destination imagery through the leans of favourite destination (FD) concepts and autobiographical memory. The second paper "Mountain tourism research. A review", by María de la Cruz del RíoRama, Claudia Patricia Maldonado-Erazo, Amador Durán-Sánchez and José Álvarez-
García, evaluates the current state of research on mountain tourism by reviewing publications in Scopus and Web of Science. Finally, the third contribution, "Climate change and ski industry in Pamporovo Resort, Bulgaria: an exploratory study on the tourists' perception", by Siya Cholakova and Elka Dogramadjeva deals with the relationship between climate change and winter tourism, and presents the provisional results of a survey on tourists at one of the major Bulgarian ski resorts. These contributions from different European mountain areas confirm how mountains are able to catch the interest of a vast range of tourism researchers, with the opportunity to integrate various disciplines.

We would like to conclude this brief introduction by thanking Prof. Stanislav Ivanov, and his staff, for the opportunity to be Guest Editors of this special issue section. Their engagement in promoting EJTR as a benchmark is witnessed by the rigorous approach in the selection process.

\section{References}

United Nations Environment Program - UNEP (2007). Tourism and Mountains. A Practical guide to managing the environmental and social impacts of mountain tourism. UNEP: Paris (France), ISBN: 978-92-807-2831-6

United Nations Environment Program - UNEP; University of Geneva; University of Bern (2014). Tourism in mountain regions. Hopes, fears and realities. University of Geneva: Geneva (Switzerland), ISBN 978-2-88903027-9

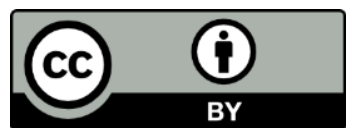

GUEST EDITORIAL
This work is licensed under the Creative Commons Attribution 4.0 International (CC BY 4.0). To view a copy of this license, visit https://creativecommons.org/licenses/by/4.0/ 